\title{
Effects of supervised movie appreciation on the improvement of college students' life meaning sense
}

\author{
Xinqiang Wang ${ }^{1,2}$, Dajun Zhang ${ }^{1,2 *}$, Jinliang Wang ${ }^{1,2}$, Hui $\mathrm{Xu}^{1,2}$, Min $\mathrm{XiaO}^{1,2}$ \\ ${ }^{1}$ Center for Student's Mental Health Education, Southwest University, Chongqing, China; \\ *Corresponding Author: zhangdj@swu.edu.cn \\ ${ }^{2}$ Research Institute of Educational Science; Southwest University, Chongqing, China
}

Received 27 December 2009; revised 20 March 2010; accepted 23 March 2010.

\begin{abstract}
The purpose of this study was to explore the effects of supervised movie appreciation on improving the life meaning sense among college students. The intervention combined by "pre-video, post counseling" was conducted on the experimental group, while the control group received no intervention. Results have shown that the scores on the subscales of will to meaning, life purpose, life control, suffer acceptance and on the total scale have improved significantly. No gender difference was found on the intervention effect, and participants receiving intervention maintained higher level on related subscales a week later, indicating that supervised movie appreciation is an effective way to improve the life meaning sense among college students.
\end{abstract}

Keywords: College Students; Life Meaning Sense; Supervised Movie Appreciation; Suicide Prevention; Mental Health Education

\section{INTRODUCTION}

The life meaning theory proposed by Frankl is of great importance in the studies of life meaning. According to Frankl's proposal, many mental disorders among college students, such as depression, emptiness, and loneliness and suicide behavior are caused by a lack of life meaning, namely, a negative mental state resulted from a mere pursuit towards natural life itself while lacking goals of life spiritual values [1]. Other studies also have shown that the life meaning plays an important role in preventing mental illness, preventing suicide, achieving mental health and improving the adaptability to the changing living environment. It can continuously predict the mental status and play a unique and irreplaceable role in case of crisis and serious frustration [1-5]. Therefore, it may effectively prevent college students' mental illness and suicide and maintain a mental healthy state, by implementing active intervention for college students [6,7]. However, few empirical studies in the psychology arena have been conducted to explore the effective ways to achieve this goal.

Educators are, in recent years, increasingly focusing on the integration of multiple approaches and modes to improve teenager's mental health [8] and strive to expand the intervention scope of mental health education for students [9]. The present education arena is in urgent need of mental health education approaches characterized by implicitness, protectiveness and permeation [10]. It is universally acknowledged that movie appreciation is an intervention approach with aforesaid advantages. Supervised movie appreciation is a psychological counseling approach by which the educators guide, on a customized basis and for certain educational objective, the participants to change the cognitive or emotional factors, including their opinions and attitudes towards themselves, the others or certain matter, develop individual's positive mental quality, relieve mental stress, prevent mental illness and eliminate mental disorders through movie appreciation and comprehension. Yuan [11] believed that individuals may gain, during the movie appreciation, the internal drive that can influence human being's emotion, thought, habit and belief, driving individuals to seek a brighter and more profound life. Meanwhile, individuals' existed values and morality is imperceptibly changed by the movie. Such influence will never end but continue throughout the life after the movie appreciation. However, the idea that movie appreciation is helpful to facilitate mental health mainly comes from theoretical explanation and empirical observation heretofore and there is few convincing empirical evidence [12-14]. Therefore, in the present study, educational experiment was used to explore the effects of supervised movie appreciation on improving students' 
life meaning sense.

\section{METHOD}

\subsection{Participants}

A class consisting of 56 students was selected at random, at a class of their optional courses, from those in Grade 1 of a college in Chongqing, China; they had never watched the film named POSTMAN IN THE MOUNTAINS. 21 boys (37.5\%) and 35 girls (62.5\%) consisted of the experimental group, with an average age of 19.67 years old and a standard age deviation of 0.92 years. For the control group, there were 46 freshmen including 20 boys (43.5\%) and 26 girls (56.5\%), who had not watched the film either. The average age for the control group was 19.64 years old and the standard age deviation was 1.01 years. Such participants were coming from different departments of the college and majoring in different subjects.

\subsection{Material}

The film named POSTMAN IN THE MOUNTAINS ${ }^{1}$, which lasted one hour and thirty minutes approximately, was produced by Xiaoxiang Film Studio and Beijing Film Studio in 1998. The movie was shown on a 120-inch projector screen in the large multi-media classroom with a capacity of 120 people.

\subsection{Measures}

We used, in the objective evaluation, the subscale "Meaning Searching and Assertion" in the total scale "the Life Attitude Profile (LAP)", a measurement developed by Ho on the basis of the central concepts of Frankl's logotherapy [2]. This subscale consists of 4 dimensions and 25 items, including will to meaning (9 items), life purpose (4 items), life control (7 items) and suffer acceptance (5 items). Likert-style 5-point rating style was adopted in the subscale, with higher score indicating higher level on life meaning. Specifically, the dimension of will to meaning is to investigate individual's motivation to seek the significance and purpose of the existence of self, the dimension of life purpose is to investigate whether an individual has clear and meaningful purpose of life and the individual's satisfaction with the life purpose, the dimension of life control is to investigate whether an individual can make choice at his/her discretion and how he/she will be responsible for the life, and

\footnotetext{
${ }^{1}$ The movie was entitled the Best Film, the Best Director and the Best Actor of the 19th Golden Rooster Awards, the People's Choice Award at the 32nd Montréal World Film Festival, the Silver Peacock Award, a Special Jury Prize, at the 31st International Film Festival of India, the Japanese Kinema Junpo Awards, the awards at the Mainichi Film Concours and the Awards of the Japanese Academy.
}

the dimension of suffer acceptance is to investigate whether an individual has understood what the suffering means and to what degree he/she may accept the suffering. The total scale has been shown to have relatively high internal consistency reliability, retest reliability, content validity and construct validity as well as certain predictive validity since the four subscales are all able to predict the "positive mental health" in general [2]. The Cronbach's Alpha coefficient for internal consistency reliability was 0.876 in the subscale selected in this study.

The subjective evaluation of participants` life meaning sense was also provided, based on the interview on the participants after watching the film, the feedback of 12 participants selected randomly by the experimenter from the experimental group, and the information reflected by participants and recorded by the experimenter during the experiment.

\subsection{Procedure and Intervention}

The intervention model composed by "pre-video, post counseling" [13] was conducted on the experimental group by means of mental health education lessons for college students, while the control group received no intervention.

\subsubsection{Pre-Video Introduction}

The slides on the projector screen demonstrated for the experimental group the theme of this movie, "love, hope, responsibility and meaning of life", and briefly introduced some important information, including the director, actors, actresses, awards obtained in China or other countries and the sensation caused abroad. However, such introduction did not disclose any plot.

\subsubsection{Pre-Test}

The experimental group was asked, by the instruction that "please write down your attitude towards the life before appreciating the movie", to fill in the "Meaning Searching and Assertion" in the "the Life Attitude Profile” before the movie was on. The subjects in the control group, who attended a class having no relation with mental health education, also took part in the pre-test.

\subsubsection{Watching the Movie}

The experimental group was watching the movie POSTMAN IN THE MOUNTAINS.

\subsubsection{Post Counseling}

The experimenter first shared with the experimental group the experiences in "beauty", "love, persistence and hope”, "belief”, “enrichment”, "beauty of simplicity and meaning of life”, "responsibility and significance of human beings" thereafter, and then asked the participants to tell their experiences in their life at their discre- 
tion. Eight participants did so. They spent 2 hours and 40 minutes in total on movie-watching and post counseling.

\subsubsection{Post-Test}

The post-test was conducted on the experimental group immediately after the post counseling and on the control group as soon as the mental health education lessons ended. The post-test for the experimental group and the control group were conducted at the same time.

\subsection{Follow-Up Study}

The same measuring was conducted on the experimental group one week after the supervised movie appreciation.

\subsection{Processing of Experimental Data}

Classify and number the pre-test and post-test of each participant's scale according to the type of groups and make statistics and analysis with SPSS13.0. Qualitative analysis was used for subjective evaluation.

\section{RESULTS}

\subsection{Scores of Experimental Group and Control Group during Pre-Test and Post-Test of Life Meaning}

Independent-samples $\mathrm{t}$ test was used to compare the sores between the experimental group and the control group on the pre-test. In the post-test, independent-samples t test was also conducted to compare the difference between control group and experimental group. Table 1 shows, in respect of the subscales and the total scale of life meaning: 1) the post-test score of the experimental group is much higher than the pre-test score $(p<0.001)$, and 2) the post-test score of the control group does not change remarkably compared with its pre-test score $(p>$ 0.05). During the pre-test, the experimental group and the control group scored almost the same in respect of the subscales and the total scale of the life meaning ( $p>$

Table 1. Scores of experimental group and control group during pre-test and post-test of college students' life meaning.

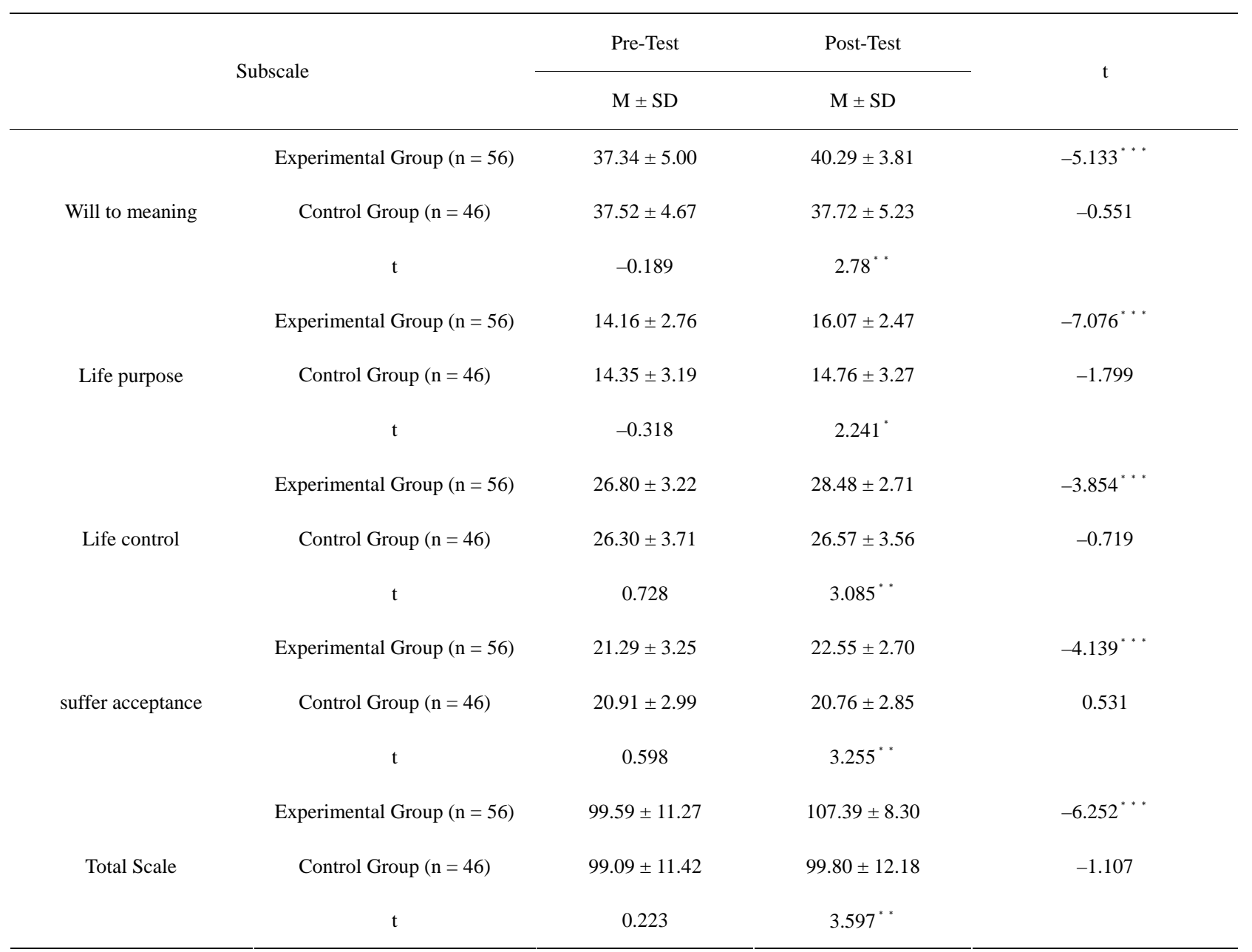

Note: "p<0.05; " $p<0.01 ;{ }^{*} " p<0.001$ 
0.05); during the post-test, the experimental group scored much higher than the control group in respect of the subscales and the total scale of the life meaning $(p<0.05)$.

\subsection{Average Increase of Post-Test Scores over Pre-Test Scores of Experimental Group and Control Group}

Such increase was obtained by post-test scores minus pre-test scores of experimental group and control group. The independent-samples t test was then used to verify and compare the difference between the average increases of the two groups. Results have shown that the increase of the experimental group's scores on all subscales and the total scale of life meaning is much higher than that of the control group ( $p>0.05$ ) (Table 2).

\subsection{Analysis on Gender Effect during the Supervised Movie Appreciation of Experimental Group}

We took all subscales and the total scale on college students' life meaning, including two dependent variable of pre-test and post-test, as the within-subjects factors and took the gender, including two value label of female and male, as the between-subjects factors. We used the repeated measures ANOVA to examine whether there was the main effect of gender during the supervised movie appreciation experiment. Results have shown that the main effects of gender were unremarkable for the four subscales, including will to meaning, life purpose, life control and suffer acceptance, and the total scale. They were respectively $\mathrm{F}(1,18.229)=0.599, p=0.442 ; \mathrm{F}(1$, $5.601)=0.476, p=0.493 ; \mathrm{F}(1,1.371)=0.109, p=$ $0.743 ; \mathrm{F}(1,30.672)=2.055, p=0.158 ; \mathrm{F}(1,121.072)=$ $0.792, p=0.377$. The results showed that gender had no significant effects on the scores.

\subsection{Comparison between the Post-Test Score of the Experimental Group for the First Time and the Post-Test Score One Week Later}

We conducted the post-test again one week following the experiment to find out whether the effect of this intervention experiment was sustainable (1 participant is absent) and compared the results with the repeatedly measured paired-samples test used for the post-test for the first time. Then we found that there was no significant difference between the scores of the two post-tests $(p>0.05)$. This demonstrates that the intervention still have effect on students' life meaning sense one week later (Table 3).

\subsection{Subjective Evaluation}

The participants were all conscientiously watching the movie when it was on, and some participants even took the lead to applaud as the movie was over. The experimenter observed that the participants were all moved by

Table 2. Average increase of post-test scores over pre-test scores of experimental group and control group.

\begin{tabular}{|c|c|c|c|c|c|}
\hline & Will to Meaning & Life Purpose & Life Control & Suffer acceptance & Total Scale \\
\hline $\begin{array}{c}\text { Average Increase of Experimental } \\
\text { Group }(\mathrm{n}=56)\end{array}$ & $2.95 \pm 4.30$ & $1.91 \pm 2.02$ & $1.68 \pm 3.26$ & $1.27 \pm 2.29$ & $7.80 \pm 9.34$ \\
\hline $\begin{array}{l}\text { Average Increase of Control Group } \\
\qquad(\mathrm{n}=46)\end{array}$ & $0.20 \pm 2.41$ & $0.41 \pm 1.56$ & $0.26 \pm 2.46$ & $-0.15 \pm 1.94$ & $0.72 \pm 4.40$ \\
\hline $\mathrm{t}$ & $3.870^{* *}$ & $4.120^{\circ} \cdot$ & $2.434^{*}$ & $3.331^{\circ}$ & $4.730^{* * *}$ \\
\hline
\end{tabular}

Note: "p<0.05; " $p<0.01 ;{ }^{\cdots}{ }^{*} p<0.001$

Table 3. Comparison between the post-test score of the experimental group for the first time and the post-test score one week later (n $=55)$.

\begin{tabular}{ccc}
\hline & Post-Test (1st Time) & Post-Test (1 Week Later) \\
\hline Will to Meaning & $40.29 \pm 3.81$ & $39.84 \pm 3.96$ \\
Life Purpose & $16.07 \pm 2.47$ & $16.04 \pm 2.52$ \\
Life Control & $28.48 \pm 2.71$ & $27.88 \pm 2.95$ \\
Suffer acceptance & $22.55 \pm 2.70$ & $22.11 \pm 2.66$ \\
Total Scale & $107.39 \pm 8.30$ & 1.542 \\
\hline
\end{tabular}


the movie and have ever shed tears because their canthi were wet. Most participants indicated, during the post counseling and in their feedback, that the experimenter's pre-video introduction played an important role in stimulating their interest. For example, a student surnamed Hu wrote down that "It is said that this movie can 'make all men shed tears', and this makes me interested in it. I wonder what can bring so many awards for this movie and make it so attractive?” Meanwhile, the environment of the rural areas, where the story took place, was similar to some extent to the participant's living environment. For example, a participant surnamed Wen wrote down that "It seems that the story took place in my hometown". In addition, the movie is close to our life and this is also important for the movie to receive wide identification. For example, a participant surnamed Zhang wrote down that "It is so close to my life that I feel it should be a true event instead of just a story". From the perspective of father-son relationship which has strong emotional shock, the story demonstrated many issues on life meaning, including career, love, family and responsibility. All of those also concerned the college students and may better penetrate and enlighten the participants. For example, a participant surnamed Huang and another surnamed Sheng respectively wrote down that "This is the first time that I watch a movie so conscientiously that I never miss any scene. It shocked me so much that I have received a spiritual baptism" and that "The emotion revealed is moving although the plot is plain". The experimenter guided, during the post counseling, the participants to exchange their feelings on the movie based on their experiences in the past life. Other participants applauded to reinforce the effect and emotional resonance was thus caused, which deepened the participants' comprehension on the movie and consolidated the intervention effect. To sum up, the most common words repeated by the participants were "responsibility, mission, belief, hope, expectation, and value and meaning of life", no matter whether during an immediate exchange of feelings or an after-class discussion. In addition, some participants pondered and made a further process on the movie following the experiment. For example, a participant surnamed Li wrote down that "I even pondered the movie for an extremely long time" thereafter.

\section{DISCUSSION}

The purpose of this study is to investigate the effect of supervised movie appreciation on improving college students' life meaning sense. The results have shown that the supervised movie appreciation may remarkably improve college students' life meaning sense. This is iden- tical to the idea that "movie appreciation is helpful to achieve mental health" [12-14] and preliminarily proves the idea by empirical evidence. In addition, we also found in this study that the gender did not cause significant impact on the experimental results and that there was no significant difference between the scores for the post-test one week after the experiment and the post-test for the first time. This indicates that the effect of this experiment is sustainable and further proves that supervised movie appreciation is an effective mean to improve the life meaning sense among college students.

Why the supervised movie appreciation may improve the life meaning sense among college students? The reasons are: 1) it is the precondition to control and remove irrelevant variables. For example, we selected the freshmen that have not watched the movie as the participants for the experimental group and the control group and effectively controlled the variables of such participants, including the gender, the grade and the age. 2) It assures successful intervention to make an integrated and feasible counseling proposal. This experiment was conducted in accordance with BU Hong's intervention model combined by "pre-video, post counseling" [13] and the results proved that the model was feasible and played an important role in counseling. It was helpful for the experimenter to set the intervention direction for participants to demonstrate the key words during pre-video introduction and make the participants understand their life meaning before the movie began; the participant would connect the plot with the intervention theme consciously or unconsciously when they were watching the movie. Meanwhile, the introduction of some basic information on the movie was helpful to stimulate the participant's interest as said by the participant surnamed $\mathrm{Hu}$ during the subjective evaluation. In addition, it was also helpful to consolidate the effect when individuals' attitudes formed during the intervention can be transferred to reality situations [15]. The experimenter directed the participants during the post-counseling to talk about their feelings based on their experiences and this was helpful for the participants to further comprehend, transfer and consolidate the theme of the intervention. 3) It is crucial for successful intervention to select appropriate movie. Supervised movie appreciation is helpful to achieve students' mental health, but it doesn't mean that this objective can be realized by selecting a movie at random. The key is to find an appropriate movie that can cause strong resonance [14]. Therefore, the selection of movie is extremely important and it should follow certain principle [12]. In this study we searched a movie with a theme close to the life meaning from the Internet and from various other channels before the intervention, analyzed the basic information, intro- 
duction and review of the related movies and watched and discussed the movie before making determination. Finally, we selected POSTMAN IN THE MOUNTAINS as the intervention material to improve the life meaning sense. The cultural settings of this movie is similar to the participants' living environment to some extent, the plot seems like a true story, the picture is beautiful and the music is pleasant, so it was highly accepted. The movie stimulated much of the participants' emotion and caused great shock to them via the father-son relationship. The father and the son in the movie were faced with many issues in respect of life meaning, including career, love, family and responsibility, and such issues were just those concerning most college students and frequently discussed by them. It was not only consistent with the college students' psychological characteristics, but also close to the theme of the intervention; it may better permeate the intervention and enlighten the participants. 4) It is of significant importance whether the participant identified, catharsised and insighted the theme of the intervention during the supervised movie appreciation. How can the supervised movie appreciation improve the participant's mental quality? We believe that the functions of supervised movie appreciation may be explained from psychological "identification, catharsis and insight" $[10,16]$ : the participants consciously or unconsciously, when watching the movie, regarded the characteristics of the protagonist as their own characteristics and deemed the roles in the movie as themselves to achieve identification; then they further experienced the emotional conflict and strain in the circumstances in the movie after they entered into the spirit of the character so that the self suppressed at ordinary times and their overload inhibition can be released and the emotion can be catharsised; finally, they gradually sublimated, insighted and internalized the theme of the intervention at the time of identification and catharsis under the direction of the movie, and the post-counseling and their preparation of feedback may further help them comprehend, internalize, transfer and consolidate the experimental effect.

There are still limitations in this study although it has been proved that supervised movie appreciation may effectively improve the life meaning sense among college students in the experimental group. 1) The scope for selecting participants is limited. Only a small number of freshmen were appropriate to this study. It has been proved via certain study [17] that the freshman's mental quality level is quite different from that of the college students in higher grade; therefore it needs further research and verification whether this experiment is effective to all college students. In addition, most participants receiving the intervention in this study were from rural areas and their living environment was quite similar to that in the movie, which may help such participants identify the movie and enhance the intervention effect. Therefore, it also needs further research whether this experiment is effective to the college students from urban areas. 2) Other subjective items, which were not related to the life meaning sense, should be designed as a control variable and included in the further research to make the result more reliable. 3) It also needs further research and investigation whether this experiment is effective no matter whether there is direction or not during the movie appreciation and whether such effects are the same or different.

\section{CONCLUSIONS}

The scores on the subscales of will to meaning, life purpose, life control, suffer acceptance and on the total scale have improved significantly and such improvement is sustainable to some extent. No gender difference was found on the experimental effect. Results have shown that supervised movie appreciation is an effective mean to improve the life meaning sense among college students.

\section{ACKNOWLEDGEMENTS}

This study was supported by the fund of School Social Work Safeguard System for College and Middle School Student's Mental Health (06XSH012), and supported by Key Project "Strategies on Cultivating College and Middle School Students’ Personality Traits” at Key Humanity Social Science Research Institute in Chongqing.

\section{REFERENCES}

[1] Jia, L.X. and Shi, C. (2007) Study on college students mental health and its education from the view of meaning in life. Heilongjiang Researches on Higher Education, 9, 142-145.

[2] Ho, Y.-C. (1990) The life attitude profile: A study of reliability and validity. Bulletin of National Taiwan Normal University, 35, 71-94.

[3] Li, H. (2006). Self-transcendence meaning of life moderates in the relation between college stress and psychological well-being. Acta Psychologica Sinica, 38(3), 422427.

[4] Jia, L.X. and Shi, C. (2008) Perception on meaning of life and influencing factors among 307 college students in Xuzhou. Chinese Journal of School Health, 29(5), 420-421.

[5] Fahlman, S.A., Mercer, K.B., Gaskovski, P., Eastwood, A.E. and Eastwood, J.D. (2009) Does a lack of life meaning cause boredom? Results from psychometric, longitudinal, and experimental analyses. Journal of social and clinical psychology, 28(3), 307-340,

[6] Keyes, C.L.M. and Lopez, S.J. (2002) Toward a science 
of mental health: Positive directions in diagnosis and interventions. In: Snyder, C.R. and Lopez, S.J., Eds., Handbook of Positive Psychology, Oxford University Press, New York, 45-59.

[7] Keyes, C.L.M. (2007) Promoting and protecting mental health as flourishing a complementary strategy for improving national mental health. American Psychologist, 62(2), 95-108.

[8] Chen, X. and Zhang, D.J. (2002) An exploration on integrated model of mental health education. Educational Research, 1, 71-75.

[9] Zeng, X.Q. and Zhang, D.J. (2008) A methodological reflection on mental health education and research in china-simultaneously with a discussion about the methodological value of "people in the environment". Psychological Science, 31(4), 992-994.

[10] Wang, X.Q. (2009) Application of bibliotherapy in mental health education for middle school students. Journal of Gannan Normal University, 1, 95-97.

[11] Yuan, Z.Z. (2000) On the process of movie appreciation. Journal of Southwest University for Nationalities Phi- losophy and Social Sciences, 3, 77-80.

[12] Schulenberg, S.E. (2003) Psychotherapy and movies: On using films in clinical practice. Journal of Contemporary Psychotherapy, 33(1), 35-48.

[13] $\mathrm{Bu}, \mathrm{H}$. (2005) Effects of excellent films on facilitating students' mental health. Mental Health Education for Primary and Middle School Student, 1, 34-35.

[14] Song, Y.F. and Xue, X.P. (2008) Appreciate psychological film and improve your mental health. Movie Literature, 22, 161-162.

[15] Zhou, S.Z. (2005) A commentary on Viktor Frankl's meaning treatment. Journal of Yangtze University (Social Sciences), 28(6), 105-108.

[16] Marlowe, M. and Maycock, G. (2000) Phenomenology of bibliotherapy in modifying teacher puntitiveness. The Journal of Genetic Psychology, 161(3), 325-336.

[17] Wang, T., Zhang, D.J. and Chen, J.W. (2003) A study on the developmental characteristics of present-day university students' mental quality. Psychological Science, 26(5), $847-850$. 